\title{
Giardiasis as zoonosis: between proof of principle and paradigm in the Northwestern region of São Paulo State, Brazil
}

\author{
Authors \\ Aline Cardoso Caseca \\ Volotão ${ }^{1}$ \\ Nathália Motta Delvaux \\ Ramos $^{1}$ \\ Maria Fantinatti ${ }^{1}$ \\ Marcus Vinícius Proença \\ de Moraes ${ }^{2}$ \\ Halim Atique Netto ${ }^{3}$ \\ Luciane Moreno Storti- \\ Melo $^{2}$ \\ Elenir Alves Macedo de \\ Godoy $^{2}$ \\ Andréa Regina Baptista \\ Rossit $^{4}$ \\ Octávio Fernandes ${ }^{1}$ \\ Ricardo Luiz Dantas \\ Machado ${ }^{2}$ \\ ${ }^{1}$ Instituto Oswaldo \\ Cruz, Medical Research \\ Laboratory, Fundação \\ Oswaldo Cruz, Rio de \\ Janeiro, RJ, Brazil \\ ${ }^{2}$ Faculdade de Medicina \\ de São José do Rio Preto \\ (FAMERP), SP, Brazil \\ ${ }^{3}$ Veterinary Hospital, Centro \\ Universitário de Rio Preto \\ (UNIRP), SP, Brazil \\ ${ }^{4}$ Microbiology and \\ Parasitology Department, \\ Biomedical Institute, \\ Universidade Federal \\ Fluminense (UFF), RJ, Brazil
}

Submitted on: 02/15/2011

Approved on: 02/25/2011

Correspondence to:

Ricardo Luiz Dantas

Machado

Center for Microorganism

Investigation

FAMERP

Av. Brigadeiro Faria Lima,

5416, U6

15090-000, Vila São Pedro

São José do Rio Preto,

São Paulo, Brazil

ricardomachado@famerp.br

Financial Support: $\mathrm{CNPq}$ e FIOCRUZ

We declare no conflict of interest.

(C2011 Elsevier Editora Ltda. All rights reserved.

\begin{abstract}
Objective: In order to evaluate the potential zoonotic transmission of Giardia duodenalis, isolates from humans and dogs in the Northwestern region of the São Paulo State, Brazil were characterized based on the $\beta$-giardin gene. Methods: The samples were analyzed by sequencing of the NestedPCR products. Results: The A1 and A2 subgenotypes were detected in human and dogs. Cysts of assemblage B, C and D have not been found in any isolates studied. Conclusions: These results are consistent with the view that giardiasis in the largest endemic region of the Brazil should not be seen as a single entity.
\end{abstract}

Keywords: Giardia duodenalis, beta giardin gene, genotypes, zoonosis, Brazil.

\section{INTRODUCTION}

Giardia duodenalis is a protozoan frequently found in intestinal infections causing gastroenteritis worldwide. The $G$. duodenalis is a complex of species with at least seven different assemblages. The $\mathrm{A}$ and $\mathrm{B}$ assemblages have been associated with infections in human as well as in other mammals, while the other assemblages have demonstrated to affect preferentially different animal species. ${ }^{1}$

In Brazil, a large variation in this parasite frequency has been observed and in some regions of São Paulo State, up to $40 \%$ of the population carries this protozoan. ${ }^{2}$ Few molecular studies have been conducted in Brazil and discordant results were reported. In Rio de Janeiro city, Southeastern region of Brazil, only A1 and A2 subgenotype were found in human fecal samples and A1 subgenotype was the only one detected in the domestic animals isolates. ${ }^{3}$ In the study carried out in the Southeastern of the São Paulo state, A2 subgenotype and assemblage B were detected in humans, $\mathrm{A} 1$ and $\mathrm{F}$ genotypes were found in cats, and C and $\mathrm{D}$ were observed in dog isolates. ${ }^{4}$ Hereby, we evaluated the potential zoonotic transmission of giardiasis, in the Northwestern region of the São Paulo State, Brazil.

\section{MATERIAL AND METHODS}

This work was conducted from July 2007 to October 2008 by the staff of the Center for Microorganisms Investigation, in the Infectious and Parasitic Diseases Service from Hospital de Base (HB). Genotyping analysis was performed at the Instituto Oswaldo Cruz, Medical Research Laboratory. Fifty-four adults were referred to $\mathrm{HB}$ due to gastrointestinal disorder investigation. We also evaluated five pet dog stool samples collected at the Veterinary Hospital, Centro Universitário de Rio Preto. After obtaining an informed consent from all individuals, fecal samples were examined for Giardia cysts by microscopy and immunoenzymatic assay. ${ }^{2}$ DNA was extracted using QIAamp DNA kit (Qiagen, Alemanha) and was analyzed by sequencing of the Nested-PCR products $\beta$-giardin. ${ }^{3}$

\section{RESULTS AND DISCUSSION}

All G. duodenalis isolates were assemblage A; 41 subgenotype A1 (38 human and 3 canine) and 18 subgenotype A2 (16 human and 2 canine). Cysts of assemblage B, C and $\mathrm{D}$ were not found in any isolates studied. The $\beta$-giardin sequences of the different genotypes 
found in this study were compared to already known sequences obtained from GenBank. Phylogenetic analysis of the $\beta$-giardin gene of $G$. duodenalis isolates from humans provided strong bootstrap support (100\%) for assigning genotypes $\mathrm{A}$ and $\mathrm{B}$ in different clusters. Although the G. duodenalis subgenotypes prevalence reported here can be representative of the human and household dog community-disseminated giardiasis in São José do Rio Preto, the biggest city of the Northwestern region of São Paulo State, the obtained data update information about these genotypes distribution for further comparisons within the diverse Brazilian regions and also within other developing countries.

Interestingly, both humans and dogs of this city displayed only assemblage A (subgenotypes A1 and A2). Although a previous study did not show this tendency for the assemblage A as single infection, ${ }^{4}$ our data are in agreement with other studies which had showed this assemblage as the only one detected. ${ }^{1,3}$ Moreover, since all individuals had diarrhea, our data support previous evidence that assemblage $\mathrm{A}$ is more virulent than assemblage $\mathrm{B}$. Curiously, in our work two individuals and their pet dogs were infected with cysts of subgenotype A1. Non-detection of dog-specific assemblages in our work supports the fact that in non-urban settings, they are more prevalent in the canine population. ${ }^{1}$

Therefore, we have three hypotheses to explain these findings: I) genotype homogeneity in Northwestern of São Paulo State is probably due to a common origin, since all fecal samples came from the same clinical laboratory and the individuals live in close geographic areas; II) the huge variation of social, climatic, and geographic features in Brazil has been reported in several studies regarding diarrhea etiology as important factors that adjust the frequency of different pathogens, ${ }^{2}$ which can explain the difference observed between our results and those found by Souza et al., ${ }^{4}(450 \mathrm{~km}$ away from the study area); III) since the Brazilian population has a highly heterogeneous ethnic composition, as result of the hybridization of the numerous native indigenous populations with immigrants from Europe, Africa and Asia and the immigration flow was not uniform in the country, the distribution of these genotypes could be related to the host-parasite relationship.
Even though the detection of assemblage A in humans should not be incriminated as zoonotic fecal-oral route, ${ }^{3}$ the presence of $\mathrm{A} 1$ and $\mathrm{A} 2$ subgenotypes in all isolates underscores the zoonotic potential in this region, supporting the view that giardiasis in the largest endemic areas of the Brazil should not be seen as a single entity.

\section{ACKNOWLEDGEMENTS}

We want to acknowledge all individuals enrolled in this study. The Laboratório Herta Meyer/UFRJ and NCCID/ CDC, for kindly providing positive controls. The authors also thank Dr. Marinete Póvoa for critical review and Dr. Ana Carolina Gonçalves and Dr. Carla D. Dan de Nardo for their collaboration in specimen collection. The work was funded by a grant from FAPESP (07/04040-7), CNPq and FIOCRUZ.

Ethical approval: Research board of the FAMERP (Human process -3456/2007 and animal process - 109509/2007).

\section{REFERENCES}

1. Lalle M, Pozio E, Capelli G et al. Genetic heterogeneity at the beta-giardin locus among human and animal isolates of Giardia duodenalis and identification of potentially zoonotic subgenotypes. Inter J Parasitol 2005; 35:207-13.

2. Rossit, AR, de Almeida, MT, Nogueira, CA et al. Bacterial, yeast, parasitic, and viral enteropathogens in HIV-infected children from Sao Paulo State, Southeastern Brazil. Diag Microbiol Infect Dis 2007; 57:59-66.

3. Volotão AC, Costa-Macedo LM, Haddad FSM et al. Genotyping of Giardia duodenalis from human and animal samples from Brazil using $\beta$-giardin gene: a phylogenetic analysis. Acta Trop 2007; 102:258-62.

4. Souza SL, Gennari SM, Richtzenhain LJ et al. Molecular identification of Giardia duodenalis isolates from humans, dogs, cats and cattle from the state of Sao Paulo, Brazil, by sequence analysis of fragments of glutamate dehydrogenase (gdh) coding gene. Vet Parasitol 2007; 149:258-64.

5. Zago MA, Costa FF, Tone LG et al. Hereditary hemoglobin disorders in a Brazilian population. Hum Hered 1983; 33:125-9. 